\title{
Investigating the Influence of Information Management Practices on IS Governance
}

\author{
Ioanna Constantiou $^{1}$, Sabine Madsen ${ }^{2}$, and Anastasia Papazafeiropoulou ${ }^{3}$ \\ ${ }^{1}$ Department of IT Management, Copenhagen Business School Howitzvej 60, \\ \# 5.12, DK 2000 Frederiksberg, Denmark \\ Tel.: +4538152353 \\ ic@inf.cbs.dk \\ ${ }^{2}$ Roskilde University, Universitetsvej 1, 43.2, DK-4000, Roskilde, Denmark \\ sabinemeruc. dk \\ ${ }^{3}$ Department of Information Systems and computing, Brunel University, Uxbridge, \\ UB8 3PH, United Kingdom \\ Tel.: +44 (0)1895 266035 \\ Anastasia.papazafeiropoulou@brunel.ac.uk
}

\begin{abstract}
Information technology especially through Internet applications provides tremendous possibilities to knowledge workers, in any domain, to get access to vast amounts of data. This is a development with great benefits but also some challenging implications. In other words, as the information available increases, the knowledge workers' needs to make sense of information, i.e. for, prioritizing, organizing, and interpreting information intensify. Yet, the information management practices, which are based on the user's characteristics, have not been studied extensively. In this paper we suggest the examination and explication of the information management practices used by knowledge workers today in order to provide useful insights to managers involved in IS governance in the organisation. We also introduce specific theories which can be used as a lens to analyse the knowledge workers' practices and offer useful theoretical insights into the domain. We contend that such research could provide a set of guidelines that can be adopted by organisations in order to offer their employees a structured way to deal with information management which is supported by the information technologies and systems available. We argue that our results could be useful to knowledge workers looking to exploit available information while overcoming information overload.
\end{abstract}

Keywords: Information management practices, IS governance, knowledge workers.

\section{Introduction}

Internet and social networking systems emerge every day and Internet-based communication tools such as skype, facebook, twitter and on-line meeting spaces are part of every knowledge worker's life. Thus, finding a productive way to manage information coming from all those sources becomes paramount for preserving their productivity. As new communication software systems become available every day, 
knowledge workers are struggling to find ways to cope with information overload and survive the overwhelming amount of information that is available to them. This vast amount of data available to knowledge workers has been reported to create 'pathologies of information' which are hard to overcome (Bawden and Robinson, 2009). It has been reported that as knowledge workers are exposed to an increasing amount of information, they lose their ability to concentrate, solve problems and handle every-day tasks. Consequences of the information overload may involve shrinking of creativity or even lead to a melt down of knowledge workers because of stress (Hallowell, 2005). Multi-tasking and breaking down of attention to a number of different sources of information is a typical experience of people working in an office environment. Although it has been suggested that knowledge workers need easy access to information through a single interface (Feldman, 2004) as well as the use of software tools for filtering information, little has been done by organisations to tackle a problem as big as information overload (IEEE Spectrum, 2009).

The question raised is about how we can support knowledge workers information management practices through IS governance. We emphasise the importance of studying information management practices in relation to IS governance, a topic which has only been investigated by a limited amount of researchers. We contend that there is a need for introducing formal methods and practices, supported by information systems, to be used by knowledge workers in order to cope with information overload. This could enable the knowledge workers to use information provided by the information systems more efficiently and add quality rather than confusion to the workplace. In turn, this may increase the productivity and efficiency in the organisation.

\section{Proposed Theoreatical Approach}

We conceptualize information management as double-edged in the sense that it encompasses practices (a) for coping with information overload as well as (b) for benefitting from the use of information (information empowerment). Moreover, we draw on different theoretical approaches to address information management from different perspectives. We propose the use of three theoretical dimensions for the study of the knowledge worker information management practices and of how they are supported by the information technologies and systems available in the organisation.

1. How the knowledge worker creates meaning from online information (Sensemaking). Intention shapes attention (Weick, 1995). It is to a large extent the way the person defines her motivations, goals, priorities, and tasks at a given point in time that makes her notice and act in accordance with certain cues while ignoring other cues completely (See e.g., Choo, 1996; Solomon, 1997; Weick, 1995; Weick et al., 2005). In other words, intention strongly influences what kind of information the knowledge worker pays attention to and creates meaning from. The created meaning in turn affects the knowledge worker's decisions.

2. How the knowledge worker interacts with, and manage information available via Internet technologies, so as to make decisions (Decision-making). Humans are subject to bounded rationality which in turn affects their information 
processing abilities (Simon 1955). In the process of decision making people have to cope with the information available in a specific situation (March 1978). Internet technologies increase information availability, which in turn may empower or impede the knowledge worker. The information management strategy is shaped by the knowledge worker's cognitive processes or intuitive approaches based on heuristics (Kahneman 2003). The knowledge worker uses heuristics to reduce the cognitive effort required to deal with all the available information in the situation at hand (Bazerman 2008). However, the use of heuristics may create bounded awareness (Chugh \& Bazerman 2007) which in turn makes the knowledge worker ignore relevant, and available information (e.g., information in one's email inbox).

3. How the knowledge worker maintains a balance between a focused mind and openness to emerging and contextual information (Mindfulness). Mindfulness is a state of mind where the individual shows openness to new information and different points of view while remaining aware of the context and in control of the situation at hand (Langer, 1989). Being mindful as a knowledge worker demands a great deal of self-observation and development of decision-making strategies which are ad-hoc and always relevant to the context of work. Maintaining a mindful state of mind gives people the possibility to avoid a situation where information is either ignored or misinterpreted with adverse effects for decisionmaking (Langer, 1989). Being mindful means being aware of the diversity of tasks coming your way but also being open to experiences which have not been planned or organised. Mindfulness is also about keeping a focused attention to the task at hand and performing one-thing-at-a-time in order to keep the consecration going while welcoming new inputs if they arrive.

We use a simple case of information management, where the knowledge worker only has one task, in order to explain how the three theoretical perspectives interrelate. A knowledge worker always has a state of mind while performing a specific task. Mindfulness enables her to keep overview of all the relevant information, thus reducing the cognitive bias in accessing the necessary information for the task (i.e., be able see more information). Then, mindfulness enables her to focus on creating meaning from information relevant to the task. The next step is to evaluate the information and make a decision about the task, based on the created meaning. Here, mindfulness reduces the cognitive burden for the decision-maker because she focuses on the respective activity. It is clear that in practice, knowledge workers experience more complicated situations and multi-tasking is often required and this can be the context of our proposed study.

\section{Future Research Plan}

Our suggested research method involves a longitudinal study to investigate the proposed research problem. We have divided the research work in three phases:

In the first phase we will conduct a pilot study for understanding the knowledge worker's information management practices when using Internet-based applications. We will conduct interviews with knowledge workers from organisations in different domains. Moreover, we will conduct interviews at the top management level to identify 
the link between information management and organisational goals. The outcome of this phase will be the formation of the knowledge base about the empirical context.

In the second phase we will collect data about the knowledge workers' information management practices in the workspace. We will capture the knowledge workers' perceptions and behaviours using a triangulation of data collection techniques, such as observation, interviews and log files. Data collected over a period of time and via different techniques will allow us to understand information processing behaviour in context and to alleviate the discrepancy between intentions/perceptions and actual behaviours. Data analysis will be performed with a focus on the use of information in different processes (e.g., during project prioritisation) and the organisational implications. The outcome of the phase is a set of information management practices as well as a set of "new" heuristics that can be adopted in the organisation and used by knowledge workers.

In the third phase we assess the impact of the identified information management practices. We will invite a group of employees from the participant organisations and ask them to use the information management practices, identified in the research for a period of time. During this period we will use observations and interviews to followup on the knowledge workers' use of these practices. The observations and interviews will be structured around the information use as described in the first phase. The outcome of the phase will be a set of information management practices that are better aligned with individual and organisational goals and provide useful insights to managers involved in IS governance in the participating organisations.

\section{References}

Bawden, D., Robinson, L.: The dark side of information: overload, anxiety and other paradoxes and pathologies. Journal of Information Science 35, 180-191 (2009)

Bazerman, M.H.: Judgment in managerial decision making, 7th edn. John Wiley \& Sons, Chichester (2008)

Choo, C.W.: The Knowing Organization: How Organizations Use Information to Construct Meaning, Create Knowledge and Make Decisions. International Journal of Information Management 16(5), 329-340 (1996)

Chugh, D., Bazerman, M.H.: Bounded awareness: what you fail to see can hurt you. Mind \& Society 6, 1-18 (2007)

Feldman, S.: The high cost of not finding information (2004), http: //www. kmworld.com/articles/readarticle.aspx?articleid=95 34 (accessed on February 26, 2010)

Hallowell, E.M.: Overloaded circuits: Why Smart People Underperform. Harvard Business Review, 1-10 (2005)

IEEE Spectrum. How to beat information overload (2009), http: / / spectrum. ieee. org/computing/it/how-to-beatinformation-overload/ 0 (accessed on February 26, 2010)

Kahneman, D.: Maps of bounded rationality: Psychology for behavioral economics. American Economic Review 93(5), 1449-1475 (2003)

Langer, E.J.: Mindfulness. Da Capo, Cambridge (1989)

March, J.G.: Bounded rationality, ambiguity, and the engineering of choice. The Bell Journal of Economics 9(2), 587-608 (1978) 
Simon, H.: A behavioral model of rational choice. The Quarterly Journal of Economics 69(1), 99-118 (1955)

Solomon, P.: Discovering Information Behavior in Sensemaking, Time and Timing. Journal of American Society of Information Science 48(12), 1097-1108 (1997)

Weick, K.E.: Sensemaking in Organizations. Sage Publications, Thousand Oaks (1995)

Weick, K.E., Sutcliffe, K.M., Obstfeld, D.: Organizing and the Process of Sensemaking. Organization Science 16(4), 409-421 (2005) 